\title{
A model of acceptance factors for business intelligence in manufacturing using theoretical models
}

\author{
Ernie Mazuin Mohd Yusof ${ }^{1}$, Mohd Shahizan Othman², Lizawati Mi Yusuf ${ }^{3}$, \\ Shamini Raja Kumaran ${ }^{4}$, Ahmad Rizal Mohd Yusof ${ }^{5}$ \\ ${ }^{1}$ Universiti Kuala Lumpur, Malaysian Institute of Industrial Technology, Malaysia \\ ${ }^{2,3,4}$ School of Computing, Faculty of Engineering, Universiti Teknologi Malaysia, Malaysia \\ ${ }^{5}$ Institute of Ethnic Studies, Universiti Kebangsaan Malaysia, Malaysia
}

\begin{tabular}{l} 
Article Info \\
\hline Article history: \\
Received Dec 14, 2018 \\
Revised Feb 15, 2019 \\
Accepted Feb 27, 2019 \\
\hline
\end{tabular}

\section{Keywords:}

Acceptance factors

Business intelligence

Continuance

Manufacturing

Theoretical model

\begin{abstract}
Manufacturing organizations implemented Business Intelligence (BI) due to many advantages offered by it. The lack of research on the acceptance of BI in manufacturing motivates the initiative in this study to have an understanding of the factors that influence the acceptance of BI in manufacturing sector. Therefore, the research proposes a model which indicates the acceptance factors of BI in manufacturing. An integrated model consisting of underlying models of Technology Acceptance Model (TAM), Expectation Confirmation Theory (ECT) and Task-Technology Fit (TTF) will be developed. The new model will formulate 19 hypotheses and 11 factors contributing to the continuance and acceptance of BI. The model will be tested using quantitative and qualitative survey conducted to Malaysian manufacturing companies and validated using Structural Equation Modelling (SEM) to investigate the causal and mediating relationships between the factors. The expected result is hoping to suggest that selected factors in the model are positively related towards the acceptance of BI in manufacturing. The results are also hoping to guide future initiatives by industrial practitioners to develop and distribute BI to the manufacturing market.
\end{abstract}

Copyright (c) 2019 Institute of Advanced Engineering and Science. All rights reserved.

\section{Corresponding Author:}

Mohd Shahizan Othman, School of Computing, Faculty of Engineering, Universiti Teknologi Malaysia, 81310 Johor Bahru, Malaysia. Email: shahizan@utm.my

\section{INTRODUCTION}

Business Intelligence (BI) is claimed to overcome manufacturing problems as it is widely used in the manufacturing industry with the advantage of transforming plenty of data into information and knowledge [1]. With BI, information that came from tedious reports and spreadsheets are able to be turned into a single view and in real-time operational data [1]. The study by Shollo (2013) also claimed that the information presented and consolidated using BI is able to foresee the future trend, thus would enable the organization to plan its operation effectively. The future data that is able to be forecasted are the monthly delivery requirements and the operational data that is real-time and in a single view.

The top management team from the large number of firms support and provide resources for implementing new technologies that cover many business processes in the firms such as process management, IT governance, regulatory comliance and many others [2]. This implementation will help them to achieve their business goals, make decisions and allocate resources. Thus, investing on the BI systems are one of the initiatives taken by more and more firms now. They are useful in generating information to analyze data extensively, eventually facilitating the firms to decide on proper actions to be taken [3]. 
This makes the BI trend becomes more competitive and responsive to business demands and to improve operational performances.

\section{BUSINESS INTELLIGENCE IN MANUFACTURING}

Yusof et al. (2013) defined BI as information obtained to aid the decision making process of a business segment through the transformation of the existing data [4]. The information is presented visually to give the intended users a clear guidance for a smooth decision making process and most importantly, an accurate and fairly fast decision. Numerous organizations in the world have adopted BI due to its capability to make effective and well-timed business decisions to increase profit [5]. BI usage in manufacturing has shown an uplifting trend. The implementation of BI in manufacturing industries has helped many manufacturing organizations improved their business processes [6]. BI implementation in the manufacturing industry has given many advantages such as achievement of managerials aims, providing faster fact-based decision making that improves business processes, promoting teamwork, and even identifying potential profitable customers [7]. There are many other advantages of BI offered across manufacturing and other sectors as well [7].

\section{USER ACCEPTANCE OF BUSINESS INTELLIGENCE SYSTEM IN MANUFACTURING}

Although research has been carried out on BI system's acceptance and adoption on small enterprises (SME) [8], [9], almost none research has been done on the acceptance of BI by manufacturing. This lack of research can be attributed to the fact that BI might be rarely used or accepted by manufacturing organisations due to knowledge and resource constraints. Therefore, an understanding of the factors that influence the acceptance of BI in manufacturing sector will help researchers and industry to develop and distribute BI to the manufacturing market. Primarily, the investigations described factors that are significant leading to use, acceptance, and adoption of a technology, subsequently leading to usability.

In view of this, the research proposes a model which indicates the acceptance of BI for manufacturing order management. Many organisations have neglected the importance of soft factors. This may influence the organizational performance [10]. Hence, the purpose of this research is also to examine the impact of acceptance factors on BI system in manufacturing industries. A novel model will be proposed in this research.

\section{THE UNDERLYING MODELS}

Numerous mature models and theories have been utilized by past researchers in justifying continuance intention of technology encompassing, Unified Theory of Acceptance and Usage of Technology (UTAUT) by Venkatesh et al. (2003) [11], Theory Acceptance Model (TAM) by Davis et al. (1989) [12], Theory of Reasoned Action (TRA) by Ajzen \& Fishbein (1973) [13], Expectation - Confirmation Theory (ECT) by Oliver (1980) [14], Theory of Planned Behavior (TPB) by Ajzen (1991) [15] and Task-Technology Fit by Goodhue and Thompson (1995) [16]. Due to varying acceptance factors, identified across a number of information system research domains that focus on TAM, ECT and TTF, there is no cohesive list of BI based acceptance factors available. The aim of this study is to bridge the gap in fragmented views on BI acceptance, and explore the subject of BI acceptance by manufacturing sector.

\section{A BRIEF EXPLANATION OF TAM, ECT AND TTF}

These models (TAM, ECT and TTF) are selected attributed to their explanatory capability in justifying variances of usability in comparison to existing technology acceptance theories and models, which could lead in producing an effective model for technology acceptance concerning online platforms [14, 17]. ECT model is useful in achieving the success of implementing information system among the users. This is because the satisfaction of users in learning the system is useful in measuring the factor of continuance intention [18]. TAM is useful in assessing general activity-based systems that could explain technology acceptance effectively [19]. While TTF is useful in evaluating the degree that a technology will assist individuals based on their task requirements, with the functions of the technology incorporated in it [20]. The technology functions must be acceptable by the users in performing their tasks.

Technology Acceptance Model (TAM) pioneered by Davis et al. (1989) has been the most extensively utilized, and the earliest model in investigating technology acceptance. It was built using Theory of Reasoned Action (TRA) model. TRA justifies and envisages behavioral actions of users in certain environments. It theorizes the behavioral actions of an individual which are influenced by the intent on 
carrying them out. This conjecture is applicable to TAM as well. TAM justifies the influence of predictors on the use of users' intention to utilize a technology-equipped system which predicts either rejection or acceptance of the technology via real behavioral actions. The goal of TAM is to justify the factors leading to acceptance or rejection of the technological system. In the work of Chooprayoon et al. (2007), TAM was utilized in their investigation to justify external factors that impact the personal belief of individuals including intentions and attitudes [21]. Figure 1 depicts the TAM model.

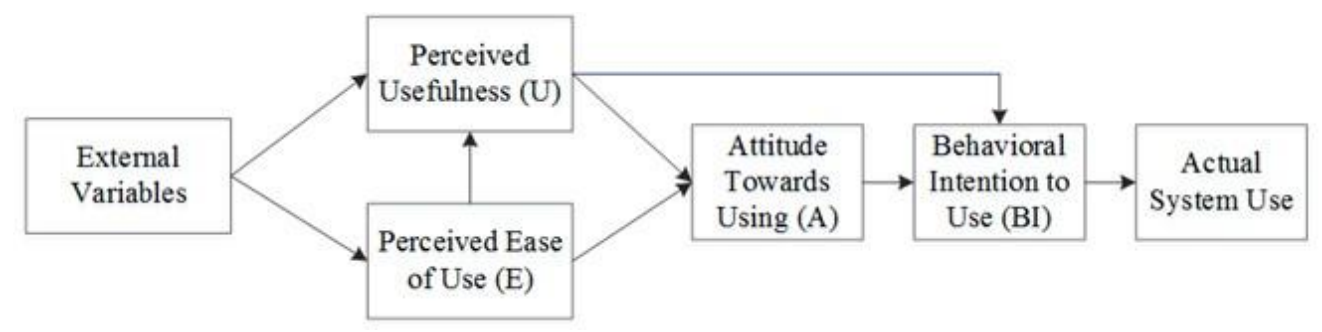

Figure 1. Theoretical acceptance model (TAM) [12]

In 1980, researchers developed ECT in marketing domain, which was designed in justifying repurchasing intention and satisfaction of customers [14]. ECT model is shown in Figure 2. It has been extended widely in studies encompassing policy studies, social psychology, and sociology. Under ECT, Cheung et al. (2005) postulated that satisfaction in purchasing is shaped by perceived performance and expectation [22]. As aforementioned, marketing domain is focused by ECT [23, 24, 14], concerning customers' behavioral actions after performing merchandise transaction, in addition to their satisfaction surrounding services provided. Recently, ECT has been utilized in information system's continuance intention studies. ECT was brought into information system studies by Bhattacherjee (2001), due to similarity exhibited in information system continuance when compared with repurchasing products in business transactions is shown in Figure 3 [25].

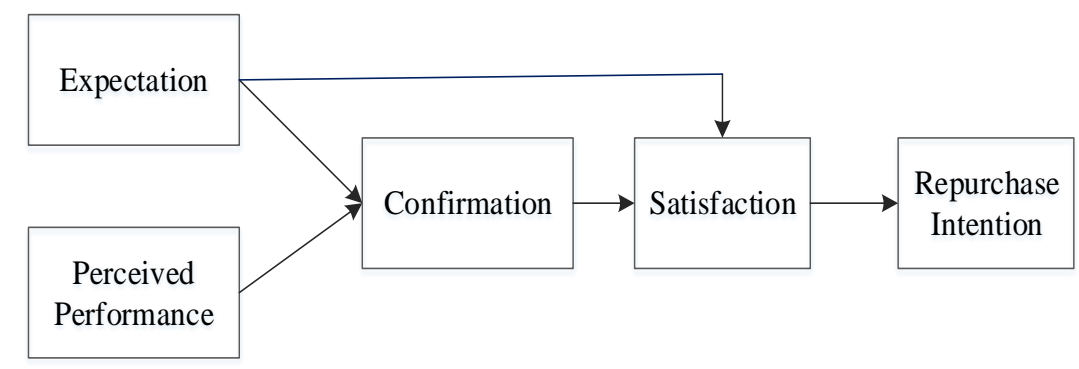

Figure 2. Expectation-confirmation theory (ECT) [14]

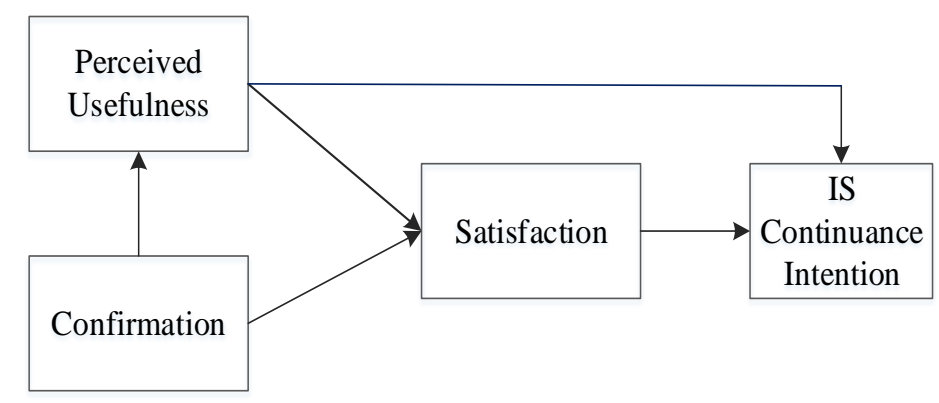

Figure 3. IS continuance model [25] 
Figure 4 shows the general model of TTF. Formulated by Goodhue \& Thompson (1995), the theory implies that the performance benefits will be gained when the features of technology match with the requirements of the tasks that must be performed [16], [26]. The performance benefits can be attained either by the individual including higher levels such as group, team and organization. This theory seems to suit the $\mathrm{BI}$ acceptance in manufacturing as the employees in manufacturing organizations are in need of a computer tool to assist them to execute their job tasks faster [27]. The study conducted by Yusof (2018) also indicated that the nature of manufacturing sector is in fast and dynamic environment, where a fast and quick decision is needed by the managers that can be obtained through fast execution of job tasks [2].

The application of elements of the TTF model can be seen in many research areas since 1995. Various domains have tested the elements in the TTF like transport and insurance, software development, managerial decision-making, e-learning, university library and social networking platform [28]. The usage of TTF in evaluating BI acceptance in manufacturing is yet to be investigated. One of the elements in TTF that is seen suitable to adapt in evaluating user acceptance towards BI is the tool functionality that is incorporated in the BI system. The tool function that exists in BI system is visual graphical display of data [4]. This is in line with a study conducted by Noor et al. 2017 who stated that to increase users' understanding towards a computer system, it is essential to include graphics in it [29]. The study also implied that the visual quality aspects of a computer system is very important. By adding the strengths of TTF with TAM and ECT will produce an integrated model that is useful for this study.

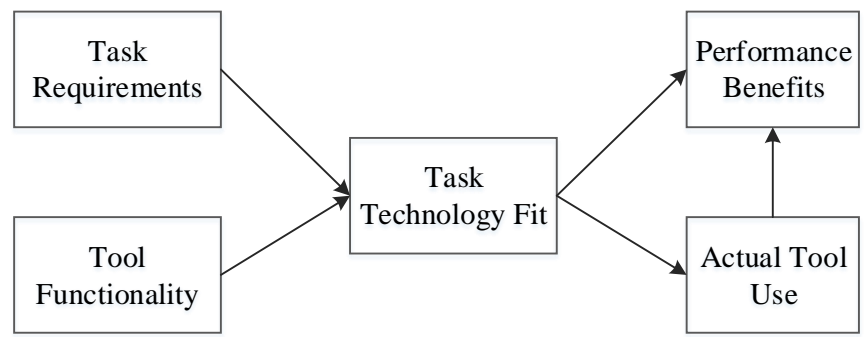

Figure 4. Task technology fit (TTF) general model [16]

\section{THE PROPOSED MODEL}

With the theoretical background of the TAM, ECT and TTF models, BI system and research motivation being discussed, this research proposes a model that recognizes various factors that attributed to the acceptance of BI system. The TAM, ECT and TTF models are incorporated into the proposed model. The model presumed that the acceptance of BI system is influenced by the continuance intention of users. Figure 5 shows the proposed model with the relationships among the constructs.

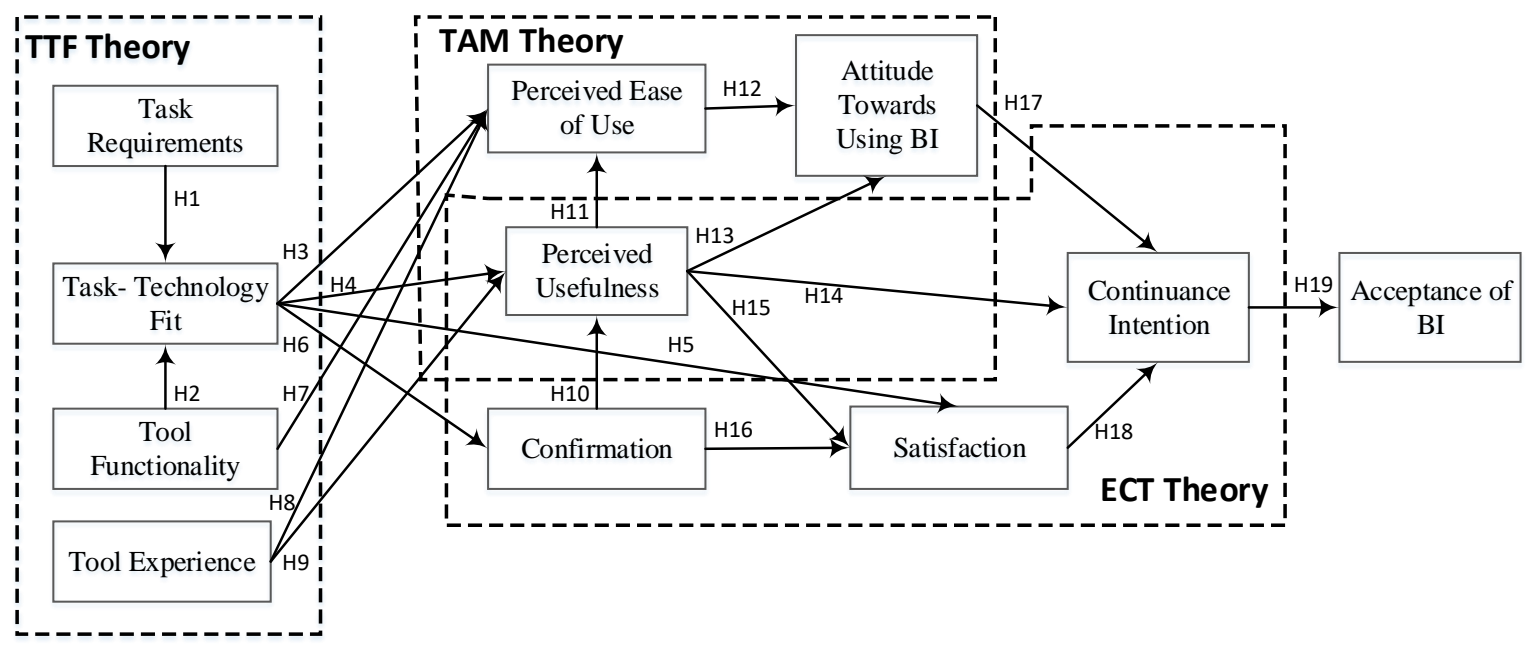

Figure 5. The proposed model 
Based on the proposed model, the following hypotheses will be formulated:

H1: There is a positive impact between task requirements and task-technology fit of BI

$\mathrm{H} 2$ : There is a positive impact between tool functionality and task-technology fit of BI

H3: There is a positive impact between task-technology fit and perceived ease of use of BI

H4: There is a positive impact between task-technology fit and perceived usefulness of BI

H5: There is a positive impact between task-technology fit and satisfaction of BI

H6: There is a positive impact between task-technology fit and confirmation of BI

H7: There is a positive impact between tool functionality and perceived ease of use of BI

H8: There is a positive impact between tool experience and perceived ease of use of BI

H9: There is a positive impact between tool experience and perceived usefulness of BI

H10: There is a positive impact between confirmation and perceived usefulness of BI

H11: There is a positive impact between perceived usefulness and perceived ease of use of BI

H12: There is a positive impact between perceived ease of use and attitude towards using BI

H13: There is a positive impact between perceived usefulness and attitude towards using BI

H14: There is a positive impact between perceived usefulness and continuance intention to use BI

H15: There is a positive impact between perceived usefulness and satisfaction of BI

H16: There is a positive impact between confirmation and satisfaction of BI

H17: There is a positive impact between attitude toward using BI and continuance intention to use BI

H18: There is a positive impact between satisfaction and continuance intention to use BI

H19: There is a positive impact between continuance intention to use BI and acceptance of BI

\section{RESEARCH METHOD}

In order to test the hypotheses formulated in the previous section, a quantitative survey will be conducted that is targeting the workers population in manufacturing sector, particularly the Malaysian manufacturing companies. Subsequent sections will discuss about the questionnaire development, data collection and data analysis.

\subsection{Questionnaire Development}

To test the theoretical model, there will be three sections in the questionnaire. The first section will use to collect the respondents' personal demographic data in the manufacturing company. The second section includes the usage of BI in the manufacturing company, while the third section consists of questions that measures the constructs in the research model.

\subsection{Data Collection}

The data collection phase is very crucial as it gathers fresh and primary information that contributes to greater understanding towards the research [30]. Knowledge proliferation can be obtained upon getting the feedback from the respondents. The target participants of this study will be the workers in Malaysian manufacturing companies who have experience in using BI system. The list of potential manufacturing companies exist in Malaysia will be studied. Subsequently, questionnaires will be distributed to the participants and their feedback will be gathered. The targetted sample size will be around 100 to 300 respondents. This is aligned with the study by many researchers who suggested that if we are to employ parametric tests, 30 to 500 subjects is the necessary sample size. However, the numbers are not applicable for non-parametric tests $[31,32]$. The 30-500 subjects are also applicable for the random sampling techniques in selecting a sample.

\subsection{Data Analysis}

Initial stage of data analysis will involve data screening as we need to remove the unusable data including outliers. The data screening process will be performed by using IBM Statistic Version 21. The next stage will will follow the data analysis done by $\mathrm{Wu} \&$ Chen (2016) that was adopted from Anderson \& Gerbing (1988) [33, 34]. Firstly, the fitness and the construct validity of the proposed model will be examined. The process will involve assessing reliability, convergent validity and discriminant validity. Secondly, the structural model will be scrutinized to study the relationships between the theoretical constructs, in terms of their strength and direction. Here, the Structural Equation Modeling (SEM) will be used together with IBM SPSS AMOS Version 23. 


\section{EXPECTED RESULTS}

The data from the quantitative survey among the workers in manufacturing companies in Malaysia who use BI will be collected and analyze. The data analysis is expected to provide a strong support and ground for all the 19 hypotheses formulated from the proposed model. The constructs generated are hoping to explain the factors influencing the users' attitude and acceptance towards using BI. The identified factors are expected to result in positive relationships among each other in accordance with the hypotheses formulated. Finally, the overall results are expected to show that integrating the TAM, ECT and TTF models can determine the factors leading to the continuance usage of BI that leads to the acceptance of using BI in manufacturing.

\section{CONCLUSION}

The lack of research on the acceptance of BI in manufacturing motivates the research to study on the understanding of the factors that influence the acceptance of BI in manufacturing sector. A new model that integrates the TAM, ECT and TTF for BI system's acceptance in manufacturing industry is developed. The idea in the model presumed that based on the constructs, several factors will contribute to the continuance usage of BI system that leads to the user acceptance of BI. To test the model, a quantitative survey will be conducted to target respondents through questionnaires that contain measurable variables for respective constructs. The next move will embark on the distribution of questionnaires to targeted respondents who are the staffs of the manufacturing companies that use BI. Analysis will be done to the data collected, as stated in section 6.3 Data Analysis. The model will be tested using SEM. The results of the analysis is hoping to suggest that selected factors in the model are positively related towards the continuance usability of BI system in manufacturing which eventually leads to the acceptance of BI system.

The contribution of the model proposed in this study does not only aim to provide valuable insights towards the existing literatures but also to assist researchers to have a better view points on users' attitutude and behavior in using BI system. Other than that, the factors for the acceptance of BI are hoping to guide future initiatives by industrial practitioners to develop and distribute BI to the manufacturing market.

\section{REFERENCES}

[1] Shollo A., "The Role of Business Intelligence in Organizational Decision-making," PhD Thesis: Danmark. Copenhagen Business School, School of Economics and Management, 2013.

[2] Kasim R, Aziati N., "The integrated framework of cloud computing implementstion in higher education institution: A review of Literature," UniKL Conference Repository. 2016.

[3] Sarma AND, Sivarama PR., "Architectural Framework for Operational Business Intelligence System," International Journal of Innovation, Management and Technology, Vol. 5, No. 4, pp. 294-300, 2014.

[4] Yusof EMM, Othman MS, Omar Y, Yusof ARM., "The Study on the Application of Business Intelligence in Manufacturing: A Review," International Journal of Computer Science Issues (IJCSI), 10(1), 317, 2013.

[5] Boonsiritomachai W, McGrath GM, Burgess S., "Exploring business intelligence and its depth of maturity in Thai SMEs," Cogent Business \& Management, 3(1), 1220663, 2016.

[6] Moniruzzaman M, Kurnia S, Parkes A, Maynard SB., "Business intelligence and supply chain agility," 2016; arXiv preprint arXiv:1606.03511.

[7] Rahaman FJ., "A Qualitative Study into the Supplier Selection Decision-Making Process in the Malaysian SME Manufacturing Industry," Doctoral Dissertation: London. University of Westminster, 2017.

[8] Song Y, Arnott D, Gao S., "Business intelligence system use in Chinese organizations," Analytics and Data Science, pp. 79-94, 2018.

[9] Qushem UB, Zeki AM, Abubakar A., "Successful Business Intelligence System for SME: An Analytical Study in Malaysia," In IOP Conference Series: Materials Science and Engineering. 2017; Vol. 226, No. 1, p. 012090.

[10] Chan SW, Ahmad MF, Kong MW., "The Impact of Soft Factors on Quality Improvement in Manufacturing Industry,” In IOP Conference Series: Materials Science and Engineering. 2017; Vol. 226, No. 1, p. 012025).

[11] Venkatesh V, Morris M, Davis G, Davis F., "User acceptance of information technology: Toward a unified view," MIS Quarterly, Vol. 24 (3), 425-478, 2003.

[12] Davis FD, Bagozzi RP, Warshaw PR., "User acceptance of computer technology: a comparison of two theoretical models," Management science, 35(8), 982-1003, 1989.

[13] Ajzen I, Fishbein M., "Attitudinal and normative variables as predictors of specific behaviors," Journal of personality and Social Psychology, 27(1), 41-57, 1973.

[14] Oliver RL., "A cognitive model of the antecedents and consequences of satisfaction decisions," Journal of marketing research, 460-469, 1980

[15] Ajzen I., "The theory of planned behaviour," Organizational behavior and human decision processes, 50(2), 179211,1991

[16] Goodhue DL, Thompson RL., "Task-technology fit and individual performance,” MIS quarterly, 213-236, 1995.

[17] Venkatesh V, Davis FD., "A theoretical extension of the technology acceptance model: Four longitudinal field studies," Management science, 46(2), 186-204, 2000. 
[18] Alraimi KM, Zo H, Ciganek AP., "Understanding the MOOCs continuance: The role of openness and reputation," Computers and Education, 80, 28-38, 2015.

[19] Wen-Chih C, Chyuan P, Chin-Chao L., "The relationship between technology acceptance model and usability test," In WASE International Conference on Information Engineering. 2009; 579-582.

[20] Vongjaturapat S., "Application of the Task-Technology Fit Model to Structure and Evaluation of the Adoption of Smartphones for Online Library Systems," Science \& Technology Asia, 23(1), 39-56, 2018.

[21] Chooprayoon V, Fung CC, Depickere A A., "TECTAM, A modified technology acceptance model to assess Ecommerce technologies adoption,” by Thai SME. In TENCON 2007-2007 IEEE Region 10 Conference. 2007; (1-4).

[22] Cheung CM, Chan GW, Limayem M., "A critical review of online consumer behavior: Empirical research," Journal of electronic commerce in organizations, 3(4), 1, 2005.

[23] Dabholkar PA, Shepherd CD, Thorpe DI., "A comprehensive framework for service quality: an investigation of critical conceptual and measurement issues through a longitudinal study," Journal of retailing, 76(2), 139-173, 2000.

[24] Anderson EW, Sullivan MW., "The antecedents and consequences of customer satisfaction for firms," Marketing science, 12(2), 125-143, 1993.

[25] Bhattacherjee A., "Understanding information systems continuance: an expectation-confirmation model," MIS quarterly, 351-370, 2001.

[26] Dishaw MT, Strong DM., "Extending the technology acceptance model with task-technology fit constructs," Information \& management, 36(1), 9-21, 1999.

[27] Yusof EMM, Othman MS, Yusof ARM., "Operational dashboard: Accelerator for shop floor workers," International Journal of Engineering \& Technology, 7(2.29) (2018) 4-6, 2018.

[28] Huang KY, Chuang YR., "Exploring business intelligence and its depth of maturity in Thai SMEs," Cogent Business \& Management, 3: 1220663, 2016.

[29] Noor HAM, Shahbodin F, Ananta GP, Mohd CKNCK, Razali SN, Khalid MS, Baharum Z., "A prototype development of visual perception diagnosis games for autism children," International Journal of Advanced and Applied Sciences, 4(3), 68-72, 2017.

[30] Baharum Z, Hanif M, Qureshi MI, Raidzuan SNM, Mahdin H., "Simulation Model on Movement of Goods in Sea Freight for Small and Medium Enterprise," Indonesian Journal of Electrical Engineering and Computer Science, 11(3), 2018.

[31] Delice A., "The Sampling Issues in Quantitative Research," Educational Sciences: Theory and Practice, 10(4), 2001-2018, 2010.

[32] Ross MR., "Introduction to probability and statistics for engineers and scientists," San Diego: Elsevier Academic Press, 218-219, 2004.

[33] Wu B, Chen X., "Continuance intention to use MOOCs: Integrating the technology acceptance model (TAM) and task technology fit (TTF) model," Computers in Human Behavior, 67, 221-232, 2017.

[34] Anderson JC, Gerbing DW., "Structural equation modeling in practice: A review and recommended two-step approach," Psychological bulletin, 103(3), 411, 1988.

\section{BIOGRAPHIES OF AUTHORS}

\begin{tabular}{|l|l|}
\hline & $\begin{array}{l}\text { Ernie Mazuin Mohd Yusof received her B. Eng. in Computer and Information Systems } \\
\text { Engineering from the International Islamic University Malaysia (IIUM) in 1999. She earned } \\
\text { MSc in Computer Science from the Universiti Teknologi Malaysia (UTM). She is currently } \\
\text { pursuing her Doctor Philosophy in UTM. She was holding a Senior Engineer post in electronics } \\
\text { manufacturing company. She is currently a lecturer in Instrumentation \& Control Engineering } \\
\text { section, Universiti Kuala Lumpur, Malaysian Institute of Industrial Technology (UniKL } \\
\text { MITEC). Her research interests cover business intelligence, manufacturing data visualization, } \\
\text { Supply Chain Management and Internet of Thing (IoT). Her current project is Business } \\
\text { Intelligence Implementation in Manufacturing'. }\end{array}$ \\
\hline & $\begin{array}{l}\text { Mohd Shahizan Othman received his BSc in Computer Science with a major in Information } \\
\text { Systems from Universiti Teknologi Malaysia (UTM), Malaysia, in 1998. Then he earned Msc in } \\
\text { Information Technology from the Universiti Kebangsaan Malaysia (UKM), Malaysia. } \\
\text { Soon after, he graduated for his PhD in Web Information Extraction, Information Retrieval and } \\
\text { Machine Learning from UKM. He is currently an Associate Professor at the School of } \\
\text { Computing, Faculty Engineering, UTM. His research interests are in information extraction and } \\
\text { information retrieval on the web, web data mining, content management, machine learning, } \\
\text { social learning, e-learning, business intelligence, and geographic information system (GIS). }\end{array}$ \\
\hline
\end{tabular}




Lizawati Mi Yusuf received her BSc in Computer Science with a major in Industrial Computing
from Universiti Teknologi Malaysia (UTM), Malaysia, in 2000. Then she earned Msc in
Information Technology from the Universiti Kebangsaan Malaysia (UKM), Malaysia. She is
currently a lecturer at the School of Computing, Faculty Engineering, UTM. Her research
interests are in optimization, web information extraction and retrieval, web data mining,
machine learning, social learning, business intelligence, high performance computing,
and numerical analysis.

